\title{
Automation of ROAD Maintenance - Development of a Roughness Measurement System for the Quality Control of Gravel Roads
}

\author{
Jussi Seppä ${ }^{1}$, Rauno Heikkilä ${ }^{2}$ \\ 1Construction Technology Research Center, Structural Design and Construction Technology \\ Laboratory, Department of Mechanical Engineering, University of Oulu; P.O.Box 4400 FIN-90014 \\ Oulu, Finland; PH +358 403586015; FAX +358 8 5534322; e-mail: jussi.seppa@oulu.fi \\ 2Construction Technology Research Center, Structural Design and Construction Technology \\ Laboratory, Department of Mechanical Engineering, University of Oulu; P.O.Box 4400 FIN-90014 \\ Oulu, Finland; PH +358 40 5385840; FAX +358 8 5534322; e-mail: rauno.heikkila@oulu.fi
}

\begin{abstract}
The main goal of this research was to develop an automatic roughness measurement system for quality control of gravel roads. The measurement system is based on the vertical acceleration sensor which is placed on the rear right suspension arm of the vehicle. The measured accelerations are collected to a terminal box which processes the data and sends it wirelessly via Bluetooth to information management software. The software runs in a mobile phone and operates with GPS. Classification of road condition is shown in real time on mobile phone screen. The measurement details are sent to server where all measuring information is available to specified user group.
\end{abstract}

Keywords: acceleration sensor, gravel road, roughness measurement, wireless data transfer

\section{Introduction}

Up to today the most common method to estimate gravel road roughness is visual observation or IRI (International Roughness Index) measurements. However, visual observation has been found to be insufficient for exact and accurate quality determination and the results are always dependent on individual surveyors. In addition, measured and computed quantities for IRI values do not give enough information what kind of roughness we in practice have. Previously research has shown that measured vertical acceleration can be better way to measure roughness of gravel roads than IRI measurement. (Lampinen 1998, 2001)

The roughness on gravel road affects driving costs and riding comfort and can be even unhealthy. The roughness increase vehicle costs such as tire and fuel cost. The roughness of road creates mechanical vibration which affects human concentration and motivation. The vibrations which are near the resonance frequency of a human's organs and body parts have the most serious influence to human. (ISO 2631-1, Marjanen 2002)

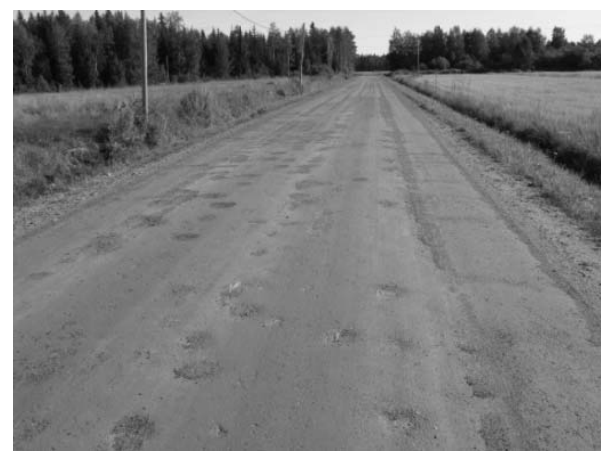

Figure 1. An example of gravel road in Finland. 
The main goal of the project was to develop impartial, efficient and road-safe measurement system which could be used in the quality control of gravel roads. More specifically, the aim was to research how this measurement device could be used in different types of cars and how tire pressure affects to measurement data. The main parts of measurement system are an acceleration sensor, a terminal box and information management software. The acceleration sensor was placed on the rear right suspension arm of the vehicle. The terminal box processes the measured data and sends the data via Bluetooth to the information management program which runs in mobile phone.

\section{Development of a roughness measurement system}

The roughness measurement system development work consisted of two main parts. The first part was research of an acceleration sensor measurement which is based on vertical accelerations of the rear right suspension arm of the vehicle. The second part was to develop the data transfer from the measurement unit to the information management program called T\&M Autori. T\&M Autori software runs in Nokia mobile phone and operates with GPS.

\subsection{Measurement equipments}

Roughness measurement system is based on the capacitive acceleration sensor (measure range $12 \mathrm{~g}$ ) which is placed the rear right suspension arm of the vehicle (figure 2). The sensor location minimizes the effect of suspension on the measurement result. The sensor measures vertical accelerations which are caused by roughness of road. The sensor must be installed in the right position, so, there there won 't be any extra measurement error. When the sensor is installed in the right position it measures one $g$ acceleration. This one $g$ acceleration changes a bit when driving the uphill but the effects on measurement result are not significant. Roughness of gravel road typically causes low-frequency vibrations to vehicle structures. It is efficient and economical to measure these oscillations by an acceleration sensor.

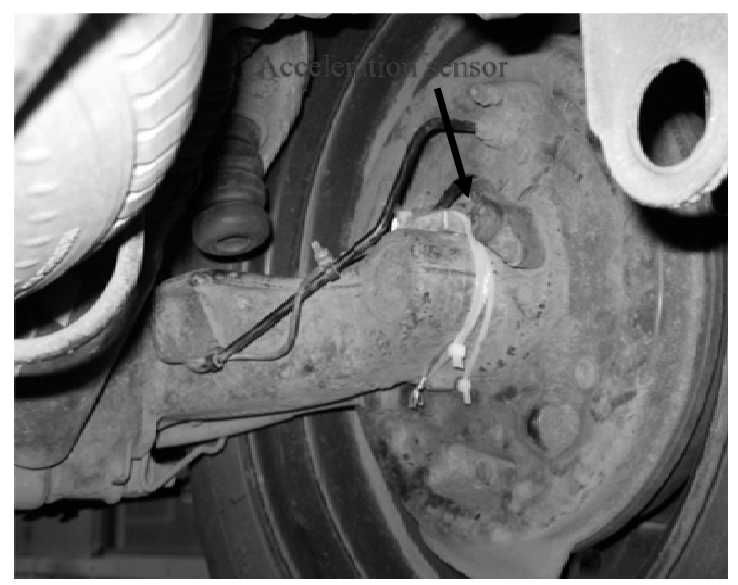

Figure 2. The acceleration sensor is placed on the suspension arm of the vehicle.

The information management program and acceleration sensor were developed separately, i.e. in the development stage of roughness meter there wasn't joint operation between the information management program and the acceleration sensor. The acceleration signal was logged to a PC by an oscilloscope. That way it was possible to research measurement more closely.

The measurement equipment also includes a terminal box (figure 3). In the development stage of the roughness meter the terminal box was not required because measurement information was logged to PC. In practice, the processor of the terminal box will later process the acceleration signal and will send information via Bluetooth to the mobile phone software.

Driving speed seriously affects seriously to measured acceleration, and must be taken into account. All measurements are modified to a reference speed $V_{\text {norm }}$ which is $60 \mathrm{~km} / \mathrm{h}$. This is the most common speed on gravel roads and typical measurement speed is usually close to $60 \mathrm{~km} / \mathrm{h}$. It is important to note that the sampling rate is constant. This results in the following formula. 


$$
k=\frac{v_{\text {norm }}}{v_{m}},
$$

where $\mathrm{k}=$ change factor, $V_{m}=$ vehicle measurement speed.

The mean value (absolute) and RMS (Root Mean Square)-value are calculated from acceleration signal by the equations 2 and 3 . Values are calculated 1.2 seconds apart, because these 1.2 seconds parts are same size than the information what terminal box will send to mobile phone software. In the development stage of roughness meter these values were calculated in post-processing and measurements were made only at the standard speed.

$$
|\bar{x}|=\frac{1}{n} \sum_{i=1}^{n}\left|x_{i}\right|
$$

$$
\begin{aligned}
& \text { where } x_{i}=\text { measured observation, } \mathrm{n}=\text { number of observations } \\
& R M S=\sqrt{\sum_{i=0}^{n} \frac{x_{i}^{2}}{n}}
\end{aligned}
$$

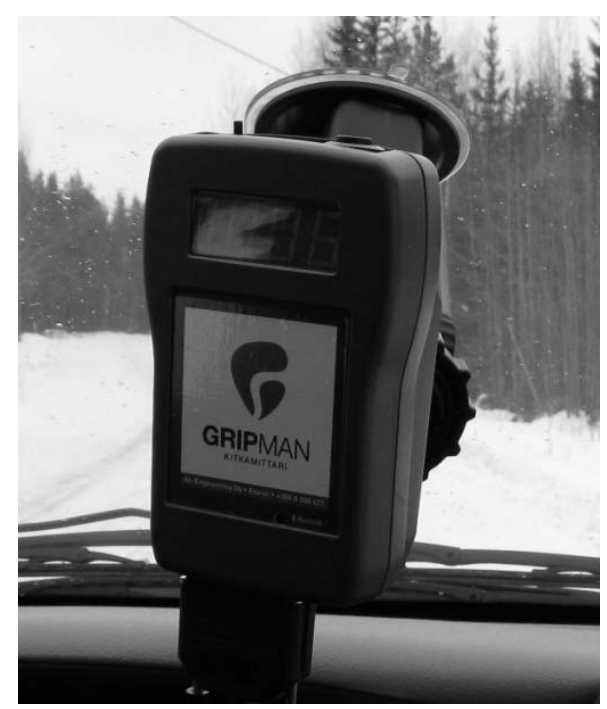

Figure 3. The terminal box.

\subsection{Measurements}

During development there were several field tests during year 2008. Different kinds of unevenness were measured to found out what kind of accelerations they cause. That way we can also research about limit values of gravel roads condition rating. Measurements were made with two different vehicles (Citroën Xsara Picasso and Volvo V70 2.5T AWD) and with different driving lines.

Another test was made with a damper testing device and the above-mentioned acceleration measurement device. The vehicle damper testing device is used in vehicle inspection at least in Finland. The damper testing device operating principle is simple. The vehicle front or rear tires are driven on a test plate which gives each tire a couple of seconds' vibration. In this case the main goal was to research how a tire pressure affects measurement results and is there any difference between two tire types. Another goal was to research how this damper testing device is applicable to calibration of the acceleration-based measurement method.

All measurements are done with a $1 \mathrm{~ms}$ sampling rate on a PC-oskiloscope program. The driving speed was kept as uniform as possible. The speed varied $40-60 \mathrm{~km} / \mathrm{h}$ but all result are transformed to reference speed $60 \mathrm{~km} / \mathrm{h}$. using factor $\mathrm{k}$ (equation 1 ).

\subsection{Development of wireless data transfer}


The terminal box sends measurement information every 1.2 second to information management program (T\&M Autori) via Bluetooth. The main task in development work was to develop an interface between the terminal box and mobile phone software. The terminal box will send processed measurment information to software. T\&M Autori software works in Nokia mobile phone and operates with GPS (figure 4). The software correlates speed and measurement data; therefore vehicle measurement speed can be variable. T\&M Autori computes roughness parameters for every 100 meters. The gravel road evenness information could be sent to a server for later review and reporting. (Tietomekka 2008)

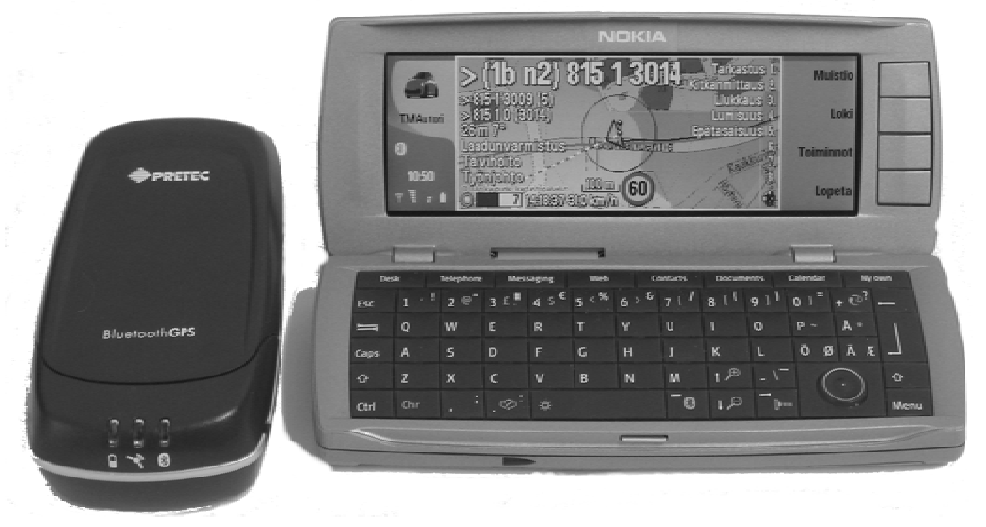

Figure 4. Wireless information gathering and recording system. (Nokia Communicator, GPS, Bluetooth, 3G).

The data management software will produce a limit value for every 100 meter. There will also be a calibration option so that it will be possible use acceleration measurement device in different vehicles. The Autori software has been tested with the acceleration device. The final report of the measurement results has been developed. The Autori will send the information via wireless to a server where the final measurement result can be visualized.

\section{Results}

\subsection{Measurements}

Figure 5 shows the acceleration signal from Finnish a gravel road. The horizontal axis is time and the vertical axis is acceleration. The measured road part was 200 meters long. The first 100 meter part was in good condition, but the end of the road was much more uneven. There were also plenty of potholes. The acceleration signal level is quite low in the first part of road. Between 7.5-9 seconds there are huge accelerations which are caused by potholes.

The same road part measurement result are shown on table 1 . The time means time from the start of measurement. The acceleration average is much higher on the second part of measured road. The road roughness clearly affects the measurement result, as desired.

The results of measurements using two different vehicle types are shown on table 2 . There is a noticeable difference between these two vehicles results. The results which are measured on the Citroën are higher than those on the Volvo. In this research the different driving line affects also to the measurement results. The results are bigger from the right border of the road than from the middle of the road centre line.

The results of tests wich are made with damper testing and acceleration measurement devices are shown in figures 6 and 7. There are no clear differences between the two tire types (normal, or with spikes). There seems to be a correlation between tire pressure and acceleration value. As a rule, when tire pressure grows the result of acceleration measurement also grows also a little bit. 


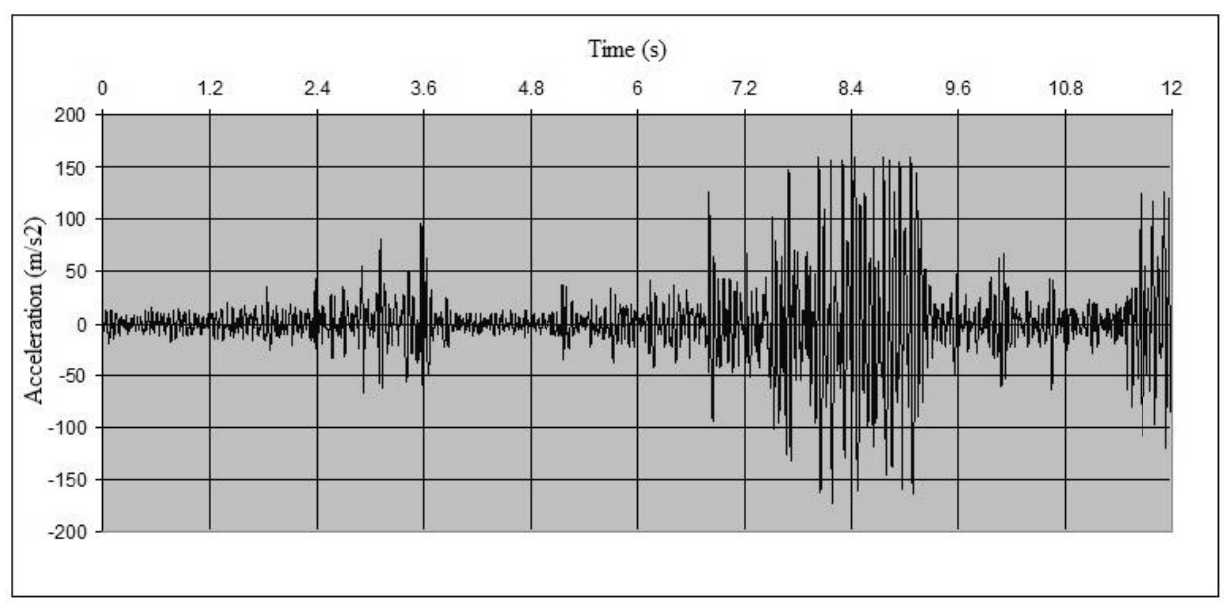

Figure 5. Acceleration signal from finnish gravel road.

Table 1. The measurement result from Finnish gravel road.

\begin{tabular}{|c|c|c|c|c|}
\hline Time [s] & $\begin{array}{c}\text { Acceleratio } \\
\text { n average } \\
\text { (absolute } \\
\text { value) } \\
{\left[\mathrm{m} / \mathrm{s}^{2}\right]}\end{array}$ & $\begin{array}{l}\text { RMS } \\
{\left[\mathrm{m} / \mathrm{s}^{2}\right]}\end{array}$ & $\begin{array}{c}\text { Acceleration } \\
\text { average of } 100 \\
\text { meter } \\
{\left[\mathrm{m} / \mathrm{s}^{2}\right]}\end{array}$ & $\begin{array}{c}\text { RMS average of } \\
100 \text { meter } \\
{\left[\mathrm{m} / \mathrm{s}^{2}\right]}\end{array}$ \\
\hline $0-1,20$ & 5.02 & 6.23 & \multirow{5}{*}{8.95} & \multirow{5}{*}{12.43} \\
\hline $1,21-2,40$ & 7.74 & 9.73 & & \\
\hline $2,41-3,60$ & 16.67 & 23.59 & & \\
\hline $3,61-4,80$ & 6.67 & 11.16 & & \\
\hline $4,81-6,00$ & 8.57 & 11.45 & & \\
\hline $6,01-7,20$ & 17.26 & 24.53 & \multirow{5}{*}{30.26} & \multirow{5}{*}{41.78} \\
\hline $7,21-8,40$ & 44.1 & 59.02 & & \\
\hline $8,41-9,60$ & 52.55 & 69.18 & & \\
\hline $9,61-10,80$ & 13.64 & 19.03 & & \\
\hline $10,81-12,00$ & 23.72 & 37.18 & & \\
\hline
\end{tabular}
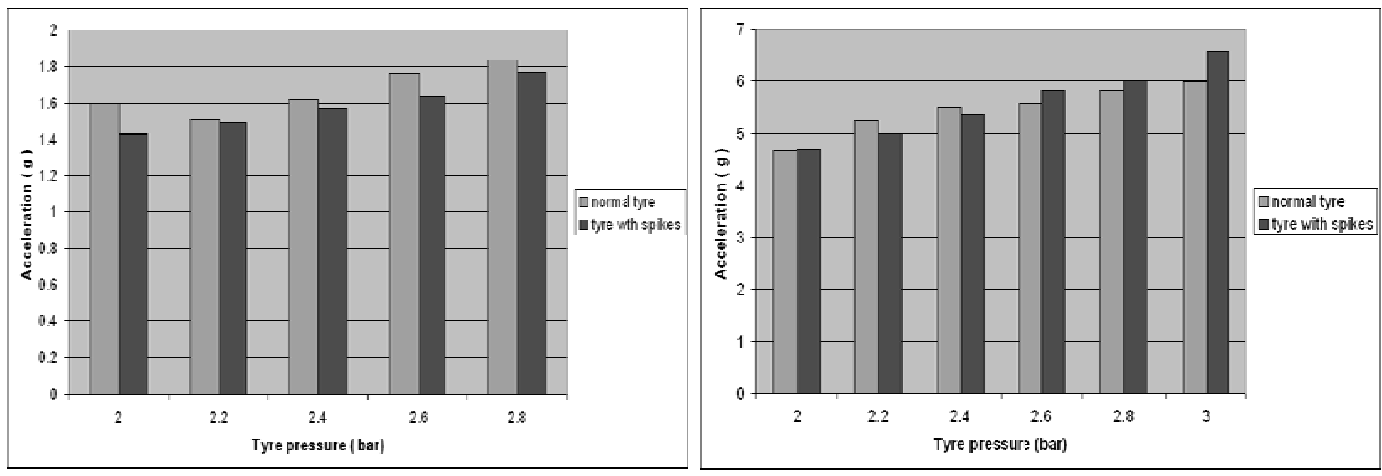

Figures 6 and 7. Left: Tire pressure effect to 1 second acceleration average value. Right: How normal and winter tire air pressure affect to maximum acceleration value. 


\subsection{Automatic roughness measurement system for quality control of gravel roads}

The developed automatic roughness measurement system consists of parts which are shown in figure 8 . The measurement information is sent to Autori-program for every 1,2 second from the terminal box. The software computes absolute average and RMS value for every 100 meter road part and compares the values to limit values. The limit values are set on different roughness of road. The result of quality control is shown in real time on a mobile phone screen (figure 8). The measurement details are sent to a server where all measurement information is available to a specified user group (figure 10). The measurement results are shown on a map based window.

Table 2. Two different vehicles measurement result from same road part. The measurement was made on three different driving lines with both vehicles. Driving line: 1 is right border of road, 2 is middle of right traveled way and 3 is middle of centre lain.

\begin{tabular}{|c|c|c|c|c|c|c|}
\hline Vehicle & $\begin{array}{c}\text { Driving } \\
\text { line }\end{array}$ & $\begin{array}{c}\text { Measurement } \\
\text { speed }[\mathrm{km} / \mathrm{h}]\end{array}$ & $\begin{array}{c}\text { Acceleration } \\
\text { average to } \\
100 \text { meter } \\
{\left[\mathrm{m} / \mathrm{s}^{2}\right]}\end{array}$ & $\begin{array}{c}\text { Acceleration } \\
\text { average of } \\
150 \text { meter } \\
\text { (absolute } \\
\text { value) } \\
{\left[\mathrm{m} / \mathrm{s}^{2}\right]}\end{array}$ & $\begin{array}{c}\text { RMS } \\
\text { average } \\
\text { of } 100 \\
\text { meter } \\
{\left[\mathrm{m} / \mathrm{s}^{2}\right]}\end{array}$ & $\begin{array}{c}\text { RMS } \\
\text { average } \\
\text { of 150 } \\
\text { meter } \\
{\left[\mathrm{m} / \mathrm{s}^{2}\right]}\end{array}$ \\
\hline Citroën & 1 & 40 & 18,90 & 17,96 & 25,63 & 23,53 \\
\hline Volvo & 1 & 40 & 13,10 & 12,13 & 17,28 & 15,91 \\
\hline Citroën & 2 & 40 & 16,44 & 14,27 & 21,25 & 18,33 \\
\hline Volvo & 2 & 40 & 12,30 & 10,17 & 15,48 & 12,91 \\
\hline Citroën & 3 & 40 & 14,41 & 12,83 & 17,99 & 16,14 \\
\hline Volvo & 3 & 40 & 11,31 & 10,03 & 14,20 & 12,61 \\
\hline Citroën & 1 & 50 & 17,88 & 16,98 & 24,37 & 22,97 \\
\hline Volvo & 1 & 50 & 12,80 & 12,29 & 16,40 & 15,70 \\
\hline Citroën & 2 & 50 & 17,14 & 15,00 & 21,66 & 19,03 \\
\hline Volvo & 2 & 50 & 11,66 & 10,45 & 14,64 & 13,19 \\
\hline Citroën & 3 & 50 & 15,46 & 13,81 & 19,41 & 17,34 \\
\hline Volvo & 3 & 50 & 12,42 & 11,33 & 15,72 & 14,51 \\
\hline
\end{tabular}

There are some rules and guidelines to this measurement method. When the measurement device has been installed on the vehicle, calibration should be done. The calibration can be done with the vehicle damper testing device. The measurement minimum driving speed is set to $30 \mathrm{~km} / \mathrm{h}$. If the measuement speed is slower than $30 \mathrm{~km} / \mathrm{h}$ there will be an error message in the measurement information. It is also recommended that the tire pressure will always be near the design value.

\section{CONCLUSION}

Experiences of the developed measurement method are promising. This kind of automatic roughness measuring device makes gravel roads' quality control easier and more reliable. The objective measurement is automatic and allows agencies to set quality levels for gravel roads maintenance.

The developed measurement method allows to efficient information collection automatically from gravel roads. The measurement operator no longer needs to be a professional. Now it is possible to store large quantities of evenness information and make different analyses. In future there will be also historical information available, which allow totally types of new analysis about gravel roads condition development. 
The developed measurement method is unique because it measures and reports about quality of gravel roads in real time, which opens many opportunities to improve condition management and quality control of gravel roads. The real time quality control also allows quick information to road users if there is for example some kind of security risk.
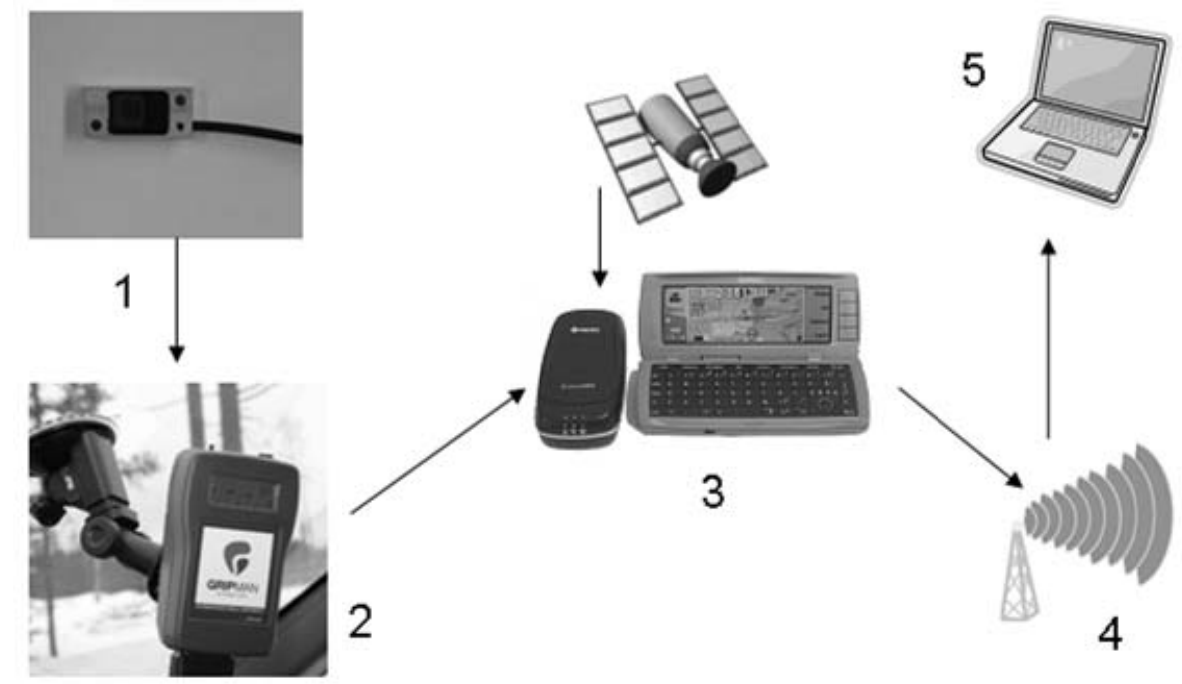

Figure 8. Parts which are included in the automatic measurement system: 1 . The acceleration sensor which is placed on the rear right suspension arm of the vehicle. 2. The terminal box which process and sends via wireless the measurement information to mobile phone. 3. Information management software which includes GPS readings. 4. The measurement results are sent to the server. 5. User can review measurement information on web.

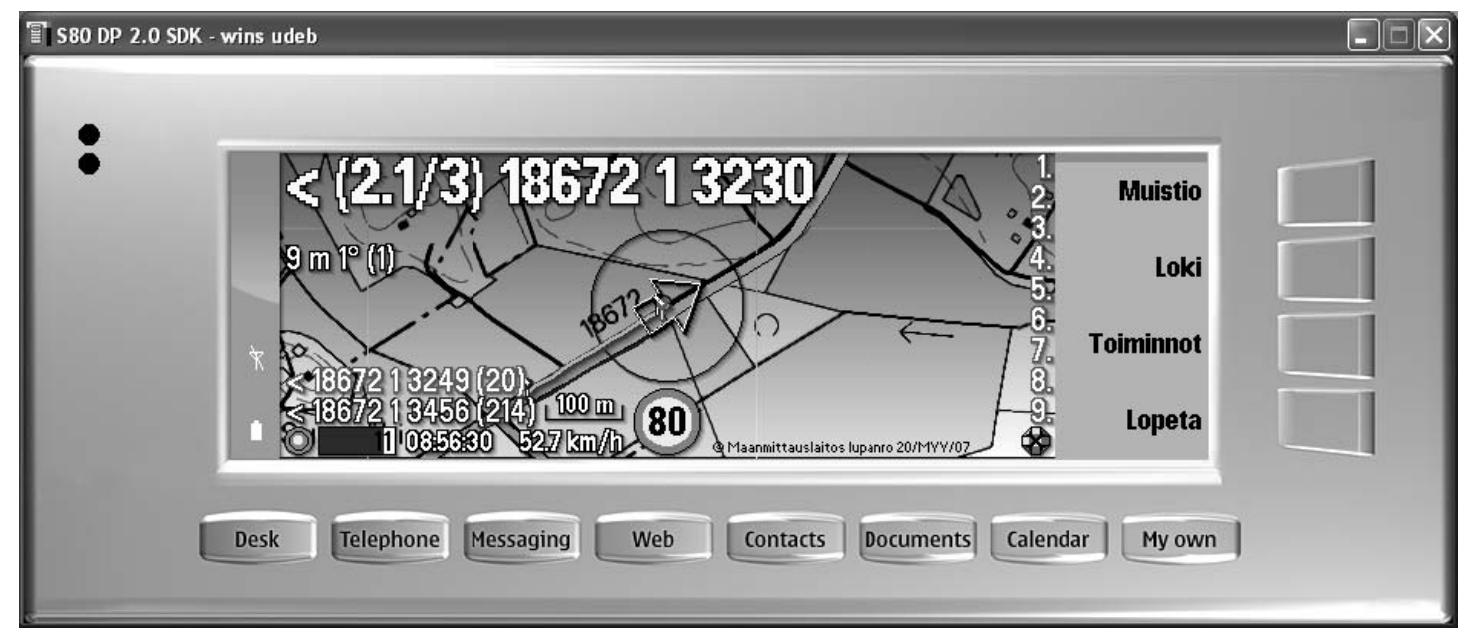

Figure 9. Classification of road condition is shown in real time on mobile phone screen. The decimal number on top of left corner shows road condition. 


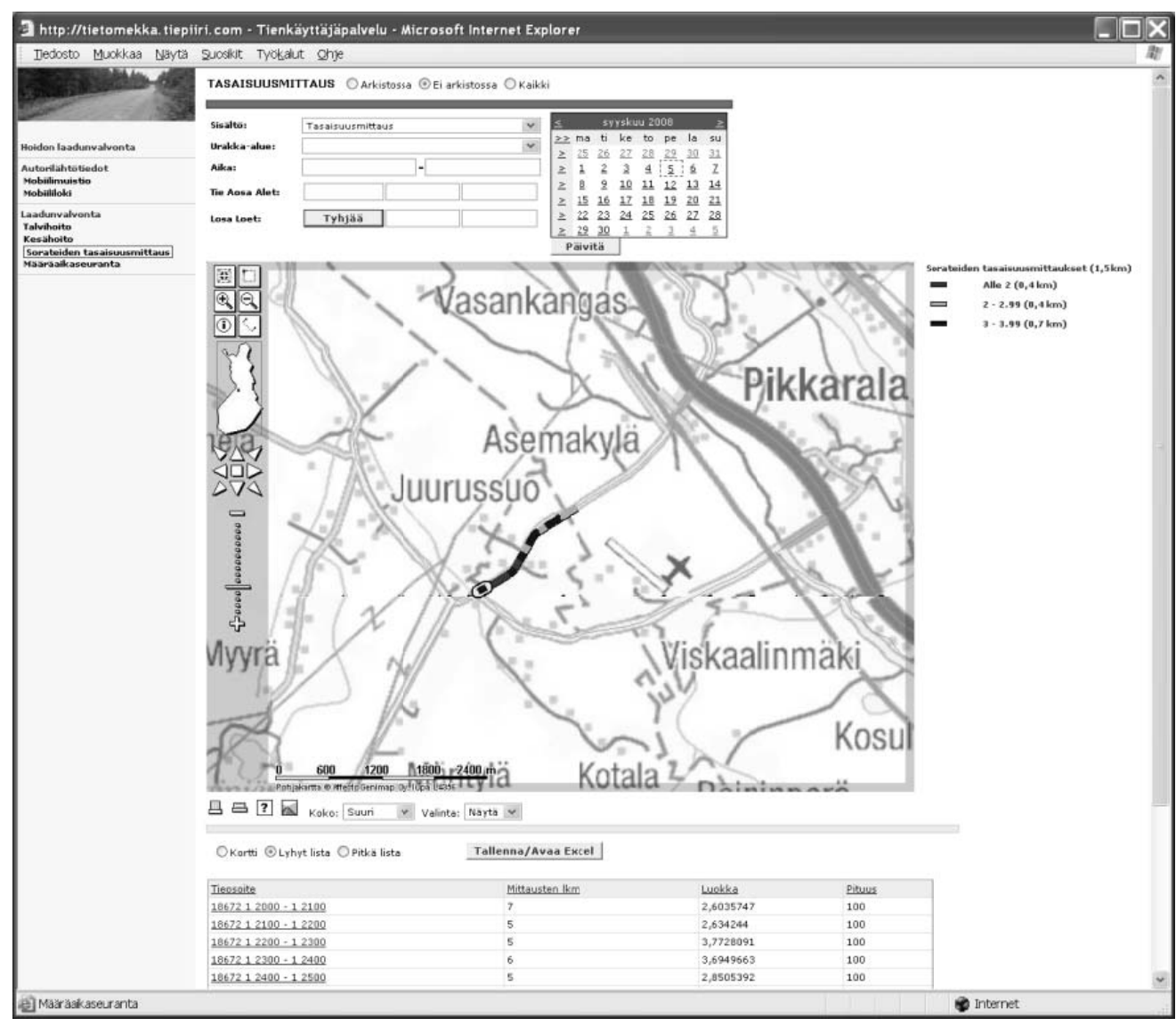

Figure 10. The measurement details are shown on web page. The map color describes the road condition.

\section{References}

[1] ISO 2631-1. (1997). Mechanical vibration and shock - Evalation of human exposure to whole-body vibration- part 1: General requirements.

[2] Lampinen, Anssi. (1998). Controlled management of gravel road, Condition rating and measuring method of gravel road. Al-Engineering Company. Research report . (in Finnish)

[3] Lampinen, Anssi. (2001). Controlled management of gravel road, Condition rating and measuring method of gravel road. Al-Engineering Company. Research report. (in Finnish)

[4] Marjanen, Ykä. (2002). Analysis of whole-body vibration on heavy vehicles. Department of Mechanical Engineering; University of Oulu, Final thesis. (in Finnish)

[5] Tietomekka company website < http://www.tietomekka.fi> (Dec. 9.2008) 